\title{
The Winners and The Losers of the Platform Economy: Who Participates?
}

By:

Lyn Hoang, University of Western Ontario (searchforlyn@gmail.com)

Dr. Grant Blank, Oxford Internet Institute (Grant.blank@gmail.com)

Dr. Anabel Quan-Haase, University of Western Ontario (aquan@gmail.com)

Keywords: Platform Economy, Digital Labor, Work, Internet

Word Count: 7423

Corresponding author:

Lyn Hoang,

647.961.2282

searchforlyn@gmail.com or lhoang3@uwo.ca

Western University, Department of Sociology, Social Science Centre room 5306, London, ON, CA, N6A 5C2 


\begin{abstract}
The platform economy is rapidly transforming the dynamics of the labor market. Optimists argue platform work functions as a social equalizer, opening opportunities for additional earnings for those who need it most. Pessimists suggest that the platform economy widens earning disparities by providing additional income to people who already have good jobs. We contribute to this debate by examining who participates in the platform economy and their motivation for participation, using a US nationally representative sample. Our findings offer support for both perspectives. Those who participated in labor-exchange platforms were more likely to come from disadvantaged backgrounds. By contrast, those who participated in online selling platforms were more likely to come from more affluent backgrounds. When we further examined different types of platform work, we found that different types of platform work were performed by different demographic and social groups. In addition, participation in some platform work, such as rideshare driving and house/laundry cleaning, is motivated out of necessity, while other platform work, such as selling used goods and performing online tasks, is generally used to supplement incomes. Distinct occupations tend to benefit different social groups in different ways and, taken together, disadvantaged groups are less likely to perform types of platform work that would improve their economic position and reduce income disparities. This tends to offer more support for the pessimist's perspective. We conclude that the platform economy is strongly segregated by occupation and it should be examined as a set of distinct occupations rather than a homogenous industry.
\end{abstract}




\section{Introduction}

Earning income online has become a global phenomenon (Huws, Spencer, \& Joyce, 2016; Graham, Hjorth, \& Lehdonvirta, 2017; Lehdonvirta, 2018). However, like other economic changes the platform economy has winners and losers. Who benefits and who loses? The answer to this question has revolved around two opposing perspectives. On the one hand, digital optimists argue that the platform economy has increased the bargaining power of workers by allowing them to transcend their local labor markets and find work globally (Fabo, Karanovic, \& Dukova, 2017). Optimists suggest that the platform economy reduces unemployment by supplying jobs to individuals who typically face barriers to labor force entry (Graham et al., 2017). Additionally, the flexibility afforded by the platform economy allows individuals to supplement their existing incomes (Drahokoupil \& Jepsen, 2017; Fabo et al., 2017), which can be a particular benefit to low-income workers in precarious jobs.

On the other hand, pessimists argue that platforms disadvantage workers because employers operate outside current regulatory frameworks, thereby reducing labor protections and workers' rights (Silberman \& Harmon, 2018; Stewart \& Stanford, 2017). Instead of providing alternative work that equalizes opportunities, the precarious, low-pay of the platform economy worsens income gaps (Drahokoupil \& Jepsen, 2017; Healy, Nicholson, \& Pekarek, 2017; Lehdonvirta, 2018). Digital inequalities often mirror existing social inequalities so that traditionally-disadvantaged groups are also disadvantaged online (Lutz, 2019). Consequently, the affluent and wealthy benefit most from the use of platforms to generate profit from their capital (Ravenelle, 2017; Schor, 2017), while disadvantaged groups rarely reap equivalent benefits (Lutz, 2019). 
Which perspective is true? Given that vast numbers of people have decided to work in the platform economy instead of working in traditional jobs, it is important to determine who actually benefits from platform work. This question is especially pressing given that inequality has risen drastically in recent decades (Wilkinson \& Pickett, 2010). If the platform economy is neutral or even reverses inequality, then governments can promote platform work as a legitimate alternative to traditional work to combat poverty and unemployment (Graham et al., 2017; Ravenelle, 2017). However, if the platform economy further benefits already advantaged social groups, the rise of platform work could exacerbate existing and emerging inequalities.

The present paper sheds light on this debate by analyzing the American Trends Panel (ATP) 2016 data, a US nationally representative sample. In his analysis of the data, A. Smith (2016) investigated the importance of demographic variables in the rate of participation in various types of platform work. We expand this descriptive investigation by drawing on occupational segregation to examine different types of platform work. We also examine how income-based needs affect participation in different types of platform work. To address these objectives, we investigate three related research questions:

RQ1: Who participates in platform work?

RQ2: Do those who participate in different types of platform work have different demographic characteristics?

RQ3: Why do people participate in platform work? How important is the income earned from platform work?

Examining platform work in the US context is important for several reasons. First, the US is leading the growth of the global platform economy (Consultancy, 2018), and many well-known 
platform companies originated in the US. In fact, American-based companies generate three quarters of the total revenue of the global platform economy (Evans \& Gawer, 2016). Important is also that the US regulatory context is distinct from other parts of the world: neoliberal employment laws allow companies to operate more freely in comparison to companies located in Europe and Asia, providing a more favorable regulatory framework for growth (Consultancy, 2018; Dittrich, 2018). In addition, van Doorn (2017) stresses the need for US studies because "with its distinct socio-economic climate and racial history, many of the issues and insights ... will also - increasingly - pertain to other Western countries" (p. 900). Thus, since the US is at the forefront of platform work it can serve as an important case study providing insight into how the platform economy intersects with existing and emerging inequalities.

\section{Literature Review}

\section{Defining the platform economy}

We follow current practice by using the term "platform economy". It has several advantages over other terms: the term is relatively neutral (Kenney \& Zysman, 2016), and it functions as an umbrella concept, encompassing a wide range of platforms (Schwellnus, Geva, Pak, \& Veidel, 2019; Vili, Kassi, Hjorth, Barnard, \& Graham, 2019). The European Commission (2016) also favors the broader term platform economy and defines it as including all business models and capital earning activities facilitated by collaborative websites, mobile apps, and social networking sites that create an open marketplace for goods or services produced and/or provided by individuals.

This broad definition of the platform economy includes: (1) one-sided business-toconsumer platforms, such as Amazon and Netflix, (2) multi-sided platforms that match workers to consumers and/or businesses on a per-service or gig basis, such as Uber and Amazon 
Mechanical Turk, and (3) multi-sided peer-to-peer platforms, such as Airbnb and eBay

(Schwellnus et al., 2019). To stress the common element of exploitation underlying platform work, scholars such as Fuchs (2014) have treated it as a homogenous industry rather than examining specific occupations. This uniform treatment of platform work overlooks differences in compensation, working hours, and the material resources and skills required to complete work. It also disregards the physical, ideological, and social impacts that different types of platform work have on the lives and bodies of workers (Fuchs, 2014). To take into account these differential impacts, we move away from treating platform work as a homogenous category, deconstructing platform work into several diverse earning opportunities with distinct outcomes (Newlands, Lutz, \& Fieseler, 2018; Schor, 2017).

\section{Perspectives on platform work}

Optimists: Platform work as a potential equalizer

Optimists point to a long list of advantages of platform work over traditional work and stress how its low entry requirements remove traditional barriers to labor market entry thereby functioning as a social equalizer (Drahokoupil \& Jepsen, 2017; Kenney \& Zysman, 2017). For example, the platform economy has simplified the process of finding and performing work so that jobseekers can begin earning immediately, bypassing long hiring or unpaid training periods (Peticca-Harris, deGama, \& Ravishankar, 2018). This benefits individuals looking to smooth the transition between traditional jobs and also those seeking to earn money while pursuing nonearning endeavors such as schooling, childcare, and caring for aging parents (Hall \& Krueger, 2018; Peticca-Harris et al., 2018). Platform companies also make earning a living easier by fostering delocalized work, remote work, and flexible work hours (Drahokoupil \& Jepsen, 2017; Fabo et al., 2017). Unemployed individuals may transcend local job shortages by working for 
transnational corporations, often while remaining in their local communities. It empowers underemployed workers, who can engage in 'skill arbitrage,' meaning they can sell their labor capabilities to global companies for more than they would earn in their local markets (Graham et al., 2017). Another equalizing feature is the zero-hour contracts offered by many platform companies, which enable individuals to work as much (or as little) as they self-determine without being penalized for stopping or restarting (Peticca-Harris et al., 2018). Control over working hours makes it easier for individuals to accommodate other social roles and responsibilities (i.e., caregiver, parent, student), which may preclude them from working traditional jobs (PeticcaHarris et al., 2018; van Doorn, 2018).

Platform work can also serve as a social equalizer by reducing economic exclusion on the basis of age, religion, race, class, gender, and disability (Graham et al., 2017). For example, entry barriers into traditional taxi and chauffeur industries make it more difficult for young people and women to obtain such work, which is why there are higher percentages of these social groups working for Uber (Hall \& Krueger, 2018).

Pessimists: Platform work as exploitation

Pessimists suggest that the platform economy promotes neoliberal economic trends and policies which treat workers as a commodity and undermine market regulations (Schor, 2017; Silberman \& Harmon, 2018). In the platform economy, individuals no longer work for a single employer, instead they perform tasks for multiple companies as self-employed contractors (Stewart \& Stanford, 2017). This deconstruction of the employer-worker relationship shifts the risk of profit or loss onto the individual (Kuhn, 2016), and erodes the responsibilities and obligations expected from employers (Drahokoupil \& Jepsen, 2017; Stewart \& Stanford, 2016). Further to adding economic risks, it excludes individuals from an array of rights and benefits 
including minimum wage, paid sick/vacation leave, parental leave, overtime pay, health insurance, pensions, and compensation from work-related illness/injury, and a right to safe working conditions (Silberman \& Harmon, 2018). In particular, when these fundamental rights are disregarded, these individuals are left alone to cope with often difficult situations.

Digital platforms atomize once whole work activities into microtasks distributed among a number of competing individuals in an aggressive global market (Drahokoupil \& Jepsen, 2017; Healy et al., 2017; Lehdonvirta, 2018). As a consequence, the platform economy does not create rewarding jobs, but rather disenfranchises workers, who wait for the next poorly paid gig to materialize online (Healy et al., 2017; Stewart \& Stanford, 2017). Delocalization of work--often viewed as an advantage of platform work--accelerates the race to the bottom by further cheapening labor. Due to delocalization, employers are no longer limited to their local market, nor do they have to physically move their operations to lower-cost countries. Employers can practice 'labor arbitrage', buying labor digitally for less (Graham et al., 2017), thereby forcing individuals to undercut one another and work for less compensation to secure work (Fabo et al., 2017; Graham et al., 2017).

In sum, optimists argue that platform work can reduce inequality or even reverse it by providing disadvantaged social groups with alternative and flexible work to help fill income or employment gaps. By contrast, pessimists contend that platform work exploits individuals and reduces their labor power which further exacerbates existing inequalities. To our knowledge, the current literature has not reconciled whether or not the platform economy benefits some social groups more than others. One way to assess these opposing views is to deconstruct platform work and use occupational segregation theory to look at different types of work. 


\section{Theoretical Framework}

Platform work has been conceptualized as a homogenous industry to stress common elements of exploitation that underlie all platform work (Fuchs, 2014). Yet, platform work contains very different ways in which people earn money. While platform work can be categorized in different ways, a useful distinction separates online selling from labor-exchange platform work (Baber, 2019; A. Smith, 2016). In labor-exchange platform work, people can quickly exchange their labor, time, and skills for income. By contrast, in online selling platform work people use their personal assets or goods to earn money. Distinguishing between these two types of platform work demonstrates that each is associated with a different set of earnings, rewards, and social status. For example, earning US\$300/night renting a luxury condo in New York City does not provide the same rewards as driving for a ridesharing company at 2 a.m. in New York City for US\$40. This motivates our investigation into who participates in what type of platform work.

To examine differential participation in types of platform work, we employ occupational segregation as our theoretical framework. Occupational segregation describes the distribution of workers across different occupations based on demographic characteristics (Tilcsik, Anteby, \& Knight, 2015), and is a key mechanism underlying inequalities within the workplace including income gaps, job authority, and allocation of promotions (Reskin, 1993). The literature suggests that two mechanisms underlie occupational segregation: sorting and self-selection.

Sorting occurs when social groups sort into particular types of work on the basis of demographic characteristics to match preexisting notions of the "appropriate" worker (Demiralp, 2011). Occupational sorting is well-established in traditional industries (Charles \& Grusky, 2004), and some evidence suggests that it is also in platform work. For example, Hall and 
Krueger (2018) found that more women work as Uber drivers than as taxi drivers, yet their representation within this industry is still considerably lower than the overall share of women in the workforce. This suggests that fewer women sort into this particular type of platform work since it is still regarded as "men's work". We propose that cultural and social norms influence who performs what type of platform work.

The second mechanism, self-selection, stresses the role of individual agency in choosing occupational roles. Individuals self-select into occupations, or rather they choose jobs that better match their behavioral disposition or their preferences for the job's characteristics including wages, social benefits, geographic location, and perceptions about the work environment (Antecol, Jong, \& Steinberger, 2008; Tilcsik et al., 2015). Research by Ayers, Banaji, and Jolls (2015) demonstrates that individuals may self-select into or out of certain platform work depending on their personal preferences or experiences with discrimination. For instance, they found evidence that prospective buyers' racial prejudice negatively impacted African-American sellers on eBay marketplace who consistently received lower bids or fewer offers for their goods in comparison to white sellers (Ayers, Banaji, \& Jolls, 2015). These researchers concluded that buyers rely on their racialized perceptions about sellers in order to minimize their risk when purchasing items that cannot be inspected beforehand (Ayers et al., 2015). This suggests that past experiences of discrimination can cause marginalized groups to go to great lengths to avoid disclosing or signaling race (Ayers et al., 2015), or these individuals may later self-select out of this work entirely, as the earnings for performing this work may not be sufficiently rewarding.

Drawing on the theoretical framework of occupational segregation, we do not see all jobs in the platform economy as equally accessible to all social groups. Even though platform work provides alternatives to traditional employment, we argue that social processes such as 
occupational segregation with mechanisms of sorting and self-selection preclude this type of work from being an equalizer.

\section{Methods}

We draw from a 2016 Pew Research Center dataset, the American Trends Panel (ATP)

Wave 19. The ATP Wave 19 allows us to effectively address the research questions because it is a nationally representative survey of US adults that provides extensive information regarding online earning activities. The final weighted sample is broadly representative of the US population (Table 1) and has been weighted in three stages to (1) adjust for differential probabilities of selection into the survey, (2) account for differential propensity to join the panel and remain active, and (3) align the sample to population benchmarks (e.g., gender, age, education, race, and daily internet usage). The survey was available in English and Spanish. To answer RQ1 and RQ2, the ATP Wave 19 contains key variables measuring a respondent's background. Most importantly, to answer RQ3, the ATP Wave 19 contains variables measuring how the income earned through platform work contributes to an individual's income needs.

\section{Sample}

The response rate for the ATP Wave 19 is acceptable: $82 \%$ and $74 \%$ for the online and paper-based versions, respectively. The combined sample comprises $N=4,579$, of which $49 \%$ were males (see Table 1). The majority of respondents were white $(78 \%)$, followed by black $(9 \%)$, Hispanic $(8 \%)$, and people who reported "other" races $(6 \%)$. The mean income for the sample was US\$35,400. Twenty-four percent of respondents reported having participated in platform work, making it an important dataset on the topic. While our sample is representative of the US population in terms of sex and region, respondents were generally older and more educated than the average US citizen (T. Smith, 2016). 
[Table 1 near here]

Measures: Dependent Variables

Platform economy as industry

We computed three variables to measure participation in the platform economy in different categories of platform work. The ATP Wave 19 included questions about respondents' participation in multi-sided platform work including labor-exchange platform work and online selling platform work (A. Smith, 2016). The ATP Wave 19 did not include questions on onesided business-to-consumer platforms because this type of platform work--like working for Netflix--is limited to a few specialized workers (e.g., film directors); thus reaching this population via an online or telephone survey would be difficult. All three dependent variables were dichotomized; non-participation was coded as " 0 " and participation was coded as " 1 ".

Our first dependent variable "participation in platform work" is based on the notion of platform work as a homogenous industry $(n=1,088)$ and measures overall participation in the platform economy in the past year. It includes participation through labor-exchange platforms and/or online selling platforms.

The second dependent variable "participation in online selling platforms" includes only people who have sold something online in the past year $(n=914)$. The third dependent variable "participation in labor-exchange platforms" examines people who have participated in laborexchange platform work $(n=401)$. The three variables allow us to disambiguate overall effects from those specific to labor-exchange platform work. It is important to note that "participation in online selling platforms" and "participation in labor-exchange platforms" are not mutually exclusive; there were 227 respondents who reported participating in both. 
Platform economy as types of work

We computed five additional variables that deconstruct types of labor-exchange platform work into "rideshare driving", "delivery", "online tasks" (e.g., coding, data entry, and taking surveys), "house/laundry cleaning", or "other platform work" (e.g., babysitting, mystery shopping, and legal services). We also computed four variables to deconstruct types of online selling into "selling used goods", "selling homemade goods", "selling consumer brands", and "selling other goods" (e.g., insurance, sports tickets, and artwork). All variables were dichotomized: " 0 " = did not engage in this type of platform work in the past year and " $1 "=$ did engage.

\section{Measures: Independent Variables}

Demographic variables. Key demographic variables include sex, age, marital status, race, education, income, citizenship status, and region. Age was coded as a four-category variable: "18-29 year-olds", “30-49 year-olds", "50-64 year-olds”, and "65+”. Marital status was recoded as: "married/cohabiting", "divorced/separated/widowed", and "never married". Race was coded as "white", "black", "Hispanic", and "other races". Education was coded as "high school degree or less", "some college", and "college graduate or higher". Self-reported earnings were also included as a continuous measure of income. A dummy variable was included to measure citizenship status and distinguished "US citizen" from "non-US citizen". This variable is relevant because the platform economy can be particularly beneficial to individuals who do not have legal visas or work permits required to work in a country (Graham et al., 2017). Region was a control variable and coded as four dummies: "Northeast", "Midwest", "South", and "West".

Income-based needs. A key independent variable in our analysis was self-reported income-needs. Respondents were asked how the income they earned contributed to satisfying 
their basic needs. We recoded this variable into two categories to distinguish clearly the importance of income: " 0 " for cases where the income was either essential or important to meeting one's basic needs, and "1" for cases where the respondent reported they can live comfortably without the additional income. For our analyses, this variable provided insights into the extent to which earnings from platform work differentially benefits individuals.

\section{Data Analysis}

We present first the weighted sample distribution for participation in the platform economy (Table 2), comparing those who did participate in platform work overall (laborexchange and/or online selling) to those who did not participate in any form of platform work. We also examine participation in labor-exchange and online selling platform work. Then, we report the logistic regression analyses (Table 3) to demonstrate which demographic factors are associated with participation in online selling and labor-exchange platform work. Finally, we present the results from logistic regressions (Table 4) on each subtype of online selling and labor-exchange platform work to show how respondents perceive the income they earn from their participation.

\section{Results}

RQ1: Who participates in platform work?

Table 2 addresses RQ1: who participates in platform work? When looking at those who did not participate in platform work in the past year, 55\% of this group were female compared to $46 \%$ of those who did participate in platform work. Fifty-three percent were over the age of 50, whereas those who engaged in platform work were younger: only $25 \%$ were over 50 years old. Those who participated in platform work were about as likely to be married or cohabiting, but they were six percentage points more likely to be never married ( $22 \%$ vs $28 \%$ ). Racial 
characteristics were within two percentage points. Those who engaged in platform work were six percentage points more likely to be college graduates (28\% vs. $35 \%)$, and 12 percentage points less likely to have no more than a high school degree. Individuals who participated in platform work also reported about US $\$ 3,000$ more in average income compared to those who did not participate $(\$ 34,700$ vs. $\$ 37,800)$.

In sum, we found differences in sex, age, education, and income between those who did not participate in any platform work and those who had. More specifically, those who participated in platform work were more likely to be male, younger (under the age of 50 years old), better educated, and have greater average incomes than those who did not participate in platform work in the past year.

[Table 2 near here]

To further examine RQ1, we examine the characteristics of respondents who participated in online selling $(70 \%)$ and those who participated in labor-exchange platform work (30\%; Table 2). We found more males participated in online selling (56\%) compared to labor-exchange platform work (47\%), this $9 \%$ represents a considerable difference in occupational segregation. In terms of age, the majority of respondents who participated in labor-exchange platform work were between 18 to 29 year-olds (41\%). By contrast, nearly $50 \%$ of those who engaged in online selling were 30 to 49 year-olds. This dropped to $38 \%$ when we examined participation in laborexchange for the same age group. Fifty-nine percent of respondents who were married or cohabiting reported engaging in online selling compared to forty-nine percent who reported participating in labor-exchange. Those who engaged in labor-exchange were also eight percentage points more likely to be never married compared to those who engaged in online selling (25\% vs 33\%). Mean incomes were considerably higher for those who participated in 
online selling (US\$40,400) in comparison to those who participated in labor-exchange platform work (US\$29,400). College graduates also show greater participation in online selling than in labor-exchange platform work, but this trend is reversed for those with high school or less. No differences in participation were found between individuals with some college. We found few regional differences for participation in online selling versus labor-exchange platform work.

In sum, we found differences across all demographic variables between participating in online selling and labor-exchange platform work. In particular, those who engage in online selling tend to come from more advantageous backgrounds: they are more likely to be male, white, middle-aged, college-educated, and have greater average incomes than those who perform labor-exchange platform work. By contrast, those who participate in labor-exchange are more likely to come from more disadvantaged backgrounds: female, under 30 years old, non-white (black, Hispanic, and other races), and have no more than a high school education. This calls for more nuanced examinations of the different types of platform work, as it cannot be viewed as a homogenous industry with equal participation across social groups.

RQ2: Do those who participate in different types of platform work have different demographic characteristics?

RQ2 is addressed in Table 3, which presents the logistic regressions predicting participation in labor-exchange platform work and online selling platform work. We comment primarily on statistically significant coefficients. When looking at participation in laborexchange platforms, 18 to 29 year-olds have greater odds of participating compared to older age groups. Those aged 30 to 49 are $42 \%$ less likely to participate in labor-exchange platforms compared to the youngest age group. More significantly, we found that those aged 50 to 64 and those aged 65 and older had much lower odds of participating, they are $79 \%$ and $91 \%$ less likely to participate, respectively. We also found that in terms of region, those living in the South are 
more than twice as likely to participate in labor-exchange platforms compared to those in the Northeast.

[Table 3 near here]

In terms of participating in online selling platforms, we found that females were $32 \%$ less likely to engage in online selling than males. Age also predicts participation in online selling, with those aged 50 to 64, and those aged 65 and older having significantly lower odds of participating than 18 to 29 year-olds. Education also plays a role in terms of online selling. Respondents with no more than a high school education have half the odds of engaging in online selling than college graduates. Interestingly, citizenship status was significant with non-US citizens having less than half the odds of participating than US citizens.

These findings reveal that there are differences in demographic characteristics of those who participate in labor-exchange and online selling platform work. To further explore whether social groups have different chances to participate in different types of platform work, and to address whether occupational segregation is occurring, we examine subtypes of platform work and RQ3 next.

RQ3: Why do people participate in platform work? How important is the income earned from platform work?

RQ3 is addressed in Table 4. We first present the logistic regressions for participation in the five types of labor-exchange platforms and the four types of online selling platforms. Then we discuss the importance of the income earned for participation in each type of platform work. Again, we comment primarily on statistically significant coefficients. Rideshare drivers are $81 \%$ more likely to be male than female. Race is the biggest predictor of driving for rideshare: black respondents were 6.1 times more likely, and individuals from other races were over 18.8 times more likely to drive than white respondents. It is important to note that due to the small number 
of respondents who reported being from other races and driving for rideshare, this odds ratio of 18.8 is unstable. Income is positively associated: each increment of income increases the likelihood of being a rideshare driver by $47 \%$.

[Table 4 near here]

Looking at online tasks in Table 4, respondents are generally younger. In particular, 18 to 29 year-olds are significantly more likely to perform this platform work than older individuals. By contrast, those who perform other platform work are older, and seniors are six times more likely to perform this work than 18 to 29 year-olds. These individuals are also highly educated; college graduates have the greatest odds of performing other platform work compared to those with less education.

Females are over three times more likely to engage in house/laundry cleaning than males. In terms of race, Hispanics have lower odds for engaging in this work compared to white respondents.

For selling used goods and homemade goods, there are no statistical differences by sex, age, marital status, race, education, and income. However, respondents living in the West are twice as likely to sell homemade goods compared to those living in the Northeast. Interestingly, the only strong predictor for selling consumer brands is race: black respondents have over six times the odds of engaging in this activity than white respondents. A noteworthy finding is that unlike the other types of selling, sellers of other goods are older. Respondents aged 50 to 64 have more than three times the odds of participating in this platform work than the youngest age group.

These findings demonstrate that the chances of participating in the various types of platform work do differ according to demographic characteristics. To provide context on why 
this may occur, we examine income needs. We found significant differences across all types of platform work. Respondents who indicate that they could live without the income earned from platform work have 3.7 and 2.7 times greater odds of performing online tasks and in selling used goods, respectively. This suggests that respondents who perceive their online earnings as neither essential nor important to meeting their basic needs are less likely to engage in any type of platform work and, if they did engage, they are more likely to perform online tasks and sell used goods. By contrast, respondents who report that they could live without the income from platform work are $81 \%, 76 \%, 63 \%$, and $71 \%$ less likely to participate in ridesharing, house/laundry cleaning, selling homemade goods, and selling other goods, respectively. In other words, those who consider their income from platform work as essential or important to meeting their income needs are more likely to participate in rideshare driving, house/laundry cleaning, selling homemade goods, and selling other goods. Income-based needs seem to have no effect on delivery, selling consumer brands, and the category of "other" platform work.

\section{Discussion}

Inequality is a pressing social problem; income inequality in OECD countries is increasing, and the size of the gap between the top and bottom $10 \%$ is unprecedented (Wilkinson \& Pickett, 2010). The platform economy has emerged as a potential equalizer, opening opportunities for new and additional earnings for low-income individuals. Despite much speculation, there is little empirical data showing who wins and who loses in the platform economy. This paper provides evidence that the platform economy in the US does not provide identical benefits for all social groups. We find that the platform economy extends traditional work dynamics using many of the same social mechanisms to recreate patterns of advantage or 
disadvantage. In other words, socioeconomic and demographic characteristics have a major impact on who performs what type of platform work.

\section{Who benefits from work in the platform economy?}

When we examine overall participation in the platform economy, it appears that those who participated in platform work come from more advantageous social backgrounds compared to those who have not participated in platform work in the past year. In particular, males, those in their middle ages, and those with a college degree or at least some college education participated in platform work at greater rates. However, these initial findings do not take into account the differential reward systems associated with distinct types of platform work. An individual selling a used item that they no longer have any use for is not the same as an individual who cleans homes in order to meet their income needs. Indeed, the platform economy is diverse not only in the types of activities performed, but in how they are compensated (Schor, 2017). Thus, when we examine labor-exchange and online selling platform work separately, we found clear differences in the individuals who participated. Those who participated in labor-exchange platforms appeared to come from more disadvantaged social backgrounds: the majority of them are nonwhite, many of them were under the age of 30 , most of them have no more than a high school education, and they also have average incomes lower than US\$30,000. This supports the digital optimists' argument that the platform economy benefits disadvantaged groups by providing them with additional earning opportunities and employment. However, when we examine the practice of selling something online as a distinct type of platform work, the platform economy becomes less favorable to disadvantaged social groups and instead benefits middle-aged individuals, those who are college-educated, and those who are white. These individuals had an average income 
greater than US\$40,000. This supports the pessimists' argument that platform work widens earning disparities by providing additional income to people who already have good jobs.

We promised at the beginning of this paper to reconcile the debate between digital optimists and pessimists for whether platform work benefits disadvantaged social groups by providing them with earning opportunities, or whether it benefits affluent individuals by providing them with opportunities to supplement their incomes. Our initial findings offer support for both perspectives because we explored work in the platform economy through distinct occupations rather than as a homogenous industry. By doing so, we are able to see that disadvantaged social groups and affluent social groups do not participate in the same types of platform work. These nuanced findings are important because they indicate that while the platform economy may benefit many social groups, it does not benefit them all equally since they do not engage in the same types of work.

\section{Occupational segregation in platform work}

To reiterate, we found that demographic variables are associated with participation in different types of platform work. For instance, 18 to 29 year-olds are more likely to engage in labor-exchange platform work than individuals over the age of 30 . By contrast, 18 to 29 yearolds are more likely to engage in online selling than individuals who are over the age of 50. As well males, college graduates, and US citizens are more likely to engage in online selling compared to females, those with no more than a high school education, and non-US citizens. These findings strongly indicate that the platform economy is occupationally segregated.

Table 4, which examines the subtypes of labor-exchange platforms and online selling platforms, further provide evidence that different social groups participate in different types of platform work. For instance, we found that men are more likely to work in rideshare driving, 
whereas women are more likely to perform house/laundry cleaning. Similarly, race predicted participation in rideshare driving, house/laundry cleaning, and the selling of consumer brands. In particular, black respondents have higher odds of performing these types of work than white respondents. By contrast, black respondents are less likely to perform other platform work compared to white respondents. We also found that age predicted participation in performing online tasks, other platform work, and selling other goods. Consequently, disadvantaged individuals and affluent individuals do not have the same likelihood of participating in each type of platform work.

The findings from Table 4 also reveal differences in how individuals regard their earnings. Individuals selling used goods or performing online tasks are more likely to use their earnings to supplement their incomes. In comparison, individuals who engage in rideshare driving, house/laundry cleaning, selling homemade goods, and selling consumer brands are more dependent on their earnings to meet their basic needs. These differences highlight that many individuals are turning to the platform economy out of necessity. However, others are using platform work to supplement their incomes, which potentially increases income inequality. Future research should continue to examine the motivations that drive individuals to enter different parts of the platform economy.

Our findings also reveal that entry barriers to platform work are not always low. For instance, individuals with above average incomes are more likely to participate in rideshare driving than those with below average incomes. A partial explanation of these findings is Ravenelle's (2017) argument that success and higher earnings in the platform economy require external material resources and skills. Working for ridesharing companies requires access to a personal vehicle and insurance, and these are barriers for individuals with low incomes. 
Taken together, these findings provide evidence against the common-goods rhetoric put forth by digital optimists. Based on these findings, we suggest that the platform economy may not help disadvantaged groups reduce the income gap by providing them access to earning opportunities because they are less likely to perform the kinds of platform work most likely to improve their economic position. In addition, by working in the platform economy instead of traditional occupations they have fewer protections and workers' rights, which may actually worsen their situations. By contrast, affluent social groups use their preexisting advantages to scoop up the better compensated work, which contributes to worsening income inequality.

The theory of occupational segregation helps explain how these patterns persist. The process of matching individuals to occupations relies in part on traditional understandings of who should perform certain types of work. Thus, mechanisms of sorting and self-selection encourage individuals to pursue certain jobs based on societal expectations of the work as men or women's work, white or non-white, and manual or non-manual. Our results support occupational segregation explanations of platform work: we found work that involves house/laundry cleaning remains women's work, while rideshare driving remains men's work and minority work.

\section{Limitations and future research}

We found evidence of occupational segregation with social groups participating differently in certain types of platform work. The strong effect of age on participation in certain types of platform work has implications for future research on differences in digital media adoption, use and mastery across age groups (Blank \& Groselj, 2014; Haight, Quan-Haase, \& Corbett, 2014). For example, older adults (65+) could benefit from obtaining supplemental income for retirement. Future research should also address why younger and older adults participate in the platform economy differently. Research across the globe has also demonstrated 
that younger adults are more likely to be online, to engage in more types of activities, and to have greater skills (Quan-Haase, Williams, Kicevski, Elueze, \& Wellman, 2018; Hargittai \& Dobransky, 2017; Hunsaker \& Hargittai, 2018). Examining the relationship between participation in the platform economy, age, and digital skills could create interventions to support adults of all ages benefit from flexible platform work. This seems particularly important given recent changes in labor force participation, with individuals continuing to work past the traditional age of 65 for retirement. Moreover, the platform economy could benefit older adults in other ways. For example, older adults can rent out parts of their homes, thereby not only earning additional income to combat poverty, but also gaining companionship (BBC News Online, 2017).

Our study has several limitations that create opportunities for follow-up research. First, while representative of the US population, our dataset is not representative of the overall global platform economy population. Future research can conduct comparative work by using crosscountry surveys to investigate how occupational segregation in the platform economy takes place in different nations and regions. Second, the dataset omits other ways in which people participate in the platform economy such as content creation. Future research can address these other ways of earning income, and determine whether these earning opportunities are equally accessible across social groups. Third, the dataset included only demographic predictor variables. Future research could examine other mechanisms that contribute to occupational segregation in platform work. Fourth, these cross-sectional data cannot demonstrate any temporal increase or decrease in income inequality. Future research employing longitudinal data could examine how platform work impacts social mobility. Finally, our research does not examine other forms of social inequality such as the differences in the experiences of women, men, and LGBTQ + individuals 
who perform the same type of platform work. For example, do women and LGBTQ+ individuals experience prejudice or fears of sexual abuse or violence when they perform 'men's work' such as driving for Uber? Future research could address these other types of inequalities as they too have implications for understanding how work in the platform economy becomes segregated.

\section{References}

Antecol, H., Jong, A., \& Steinberger, M. (2008). Sexual orientation wage gap. ILR Review, 61(4), 518-543.

Ayers, I., Banaji, M., \& Jolls, C. (2015). Race effects on eBay. The RAND Journal of Economics, 46(4), 891-917.

Baber, A. (2019). The 'sharing economy'? Planning Theory and Practice, 20(3), 435-439.

Blank, G., \& Groselj, D. (2014). Dimensions of internet use. Information, Communication \& Society, 17(4), 417-435.

BBC News Online. (2017, December). Homesharing. BBC News Website. Retrieved from https://www.bbc.com/news/av/uk-politics-42438530/homesharing-we-get-on-like-ahouse-on-fire.

Consultancy.org. (2018, October 08). UK's gig economy can learn from US' more mature freelancing market. Consultancy.uk. Retrieved from https://www.consultancy.uk/news/18953/uks-gig-economy-can-learn-from-us-moremature-freelancing-market.

Demiralp, B. (2011). Occupational self-selection in a labor market with moral hazard. European Economic Review, 55, 497-519.

Dittrich, P. (2018). Online platforms and how to regulate them. Jacques Delors Institut 227, $1-15$.

Drahokoupil, J., \& Jepsen, M. (2017). The digital economy and its implications for labor. Transfer: European Review of Labor and Research, 23(2), 103-107.

European Commission. (2016, June 02). A European agenda for the collaborative economy in 
communication. $C O M(2016) 356$ final. Retrieved from http://ec.europa.eu/DocsRoom/documents/16881.

Evans, P., \& Gawer, A. (2016, January 14). The rise of the platform entreprise (Report). New York: The Centre for Global Enterprise. Retrieved from https://www.thecge.net/?s=rise+of+platform+enterprise.

Fabo, B., Karanovic, J., \& Dukova, K. (2017). In search of an adequate European policy response to the platform economy. Transfer: European Review of Labor \& Research, 23(2), 163-175.

Fuchs, C. (2014). Digital labour and Karl Marx. New York, NY: Routledge.

Graham, M., Hjorth, I., \& Lehdonvirta, V. (2017). Digital labour and development. Transfer $23(2), 135-162$.

Charles, M., \& Grusky, D.B. (2004). Occupational ghettos. Stanford, CA: Stanford University Press.

Haight, M., Quan-Haase, A., \& Corbett, B.A. (2014). Revisiting the digital divide in Canada. Information, Communication \& Society, 17(4), 503-519.

Hall, J.V., \& Krueger, A.B. (2018). An analysis of the labour market for Uber's driver-partners in the United States. ILR Review, 71(1), 705-732.

Hargittai, E., \& Dobransky, K. (2017). Old dogs, new clicks. Canadian Journal of Communication, 42(2), 196-212.

Healy, J., Nicholson, D., \& Pekarek, A. (2017). Should we take the gig economy seriously? Labor and Industry, 27(3), 232-248.

Hunsaker, A., \& Hargittai, E. (2018). A review of internet use among older adults. New Media \& Society, 20(10), 3937-3954.

Huws, U., Spencer, N., \& Joyce, S. (2016). Crowd work in Europe. FEPS Studies, 1-51.

Kenney, M., \& Zysman, J. (2016). The rise of the platform economy. Issues in Science and Technology, 32(3), 61-69.

Kuhn, K.M. (2016). The rise of the 'gig economy' and implications for understanding work and workers. Industrial and Organizational Psychology, 9(1), 157-162.

Lehdonvirta, V. (2018). Flexibility in the gig economy. New Technology, Work and Employment, $33(1), 16-29$. 
Lutz, C. (2019). Digital inequalities in the age of artificial intelligence and big data. Human Behavavior \& Emerging Technologies, 1(2), 141-148.

Newlands, G., Lutz, C., \& Fieseler, C. (2018). Collective action and provider classification in the sharing economy. New Technology, Work and Employment, 33(3), 250-267.

Peticca-Harris, A., deGama, N., \& Ravishankar, M.N. (2018). Post-capitalist precarious work and those in the 'drivers' seat. Organization. https://doi.org/10.1177/1350508418757332

Quan-Haase, A., Williams, C., Kicevski, M., Elueze, I., \& Wellman, B. (2018). Dividing the grey divide. American Behavioral Scientist, 62(9), 1207-1228.

Ravenelle, A.J. (2017). Sharing economy workers. Cambridge Journal of Regions, Economy and Society, 10, 281-295.

Reskin, B. (1993). Sex segregation in the workplace. Annual Review of Sociology, 19, 241-270.

Schor, J.B. (2017). Does the sharing economy increase inequality within the eighty percent? Cambridge Journal of Regions, Economy, and Society, 10, 263-279.

Schwellnus, C., Geva, A., Pak, M., \& Veidel, R. (2019). Gig economy platforms. OECD Economics Department, Working Papers, 1550, 1-33.

Silberman, M.S., \& Harmon, E. (2018). Rating working conditions on digital labor platforms. Computer Supported Cooperative Work (CSCW), 28(5), 911-960.

Smith, A. (2016, November 17). Gig work, online selling and homesharing (Report). Washington, DC: Pew Research Center. Retrieved from http://www.pewinternet.org/wp-content/uploads/sites/9/2016/11/PI_2016.11.17_GigWorkers_FINAL.pdf

Smith, T. (2019, February 9). General social survey, 2016. Chicago, IL: National Science Foundation. Retrieved from http://www.thearda.com/Archive/Files/Descriptions/GSS2016.asp.

Stewart, A., \& Stanford, J. (2017). Regulating work in the gig economy. The Economics and Labor Relations Review, 28(3), 420-437.

Tilcsik, A., Anteby, M., \& Knight, C.R. (2015). Concealable stigma and occupational segregation. Administrative Science Quarterly, 60(3), 446-481. 
van Doorn, N. (2017). Platform labor. Information, Communication \& Society, 20(6), 898-914.

Wilkinson, R., \& Pickett, K. (2010). The spirit level (2nd ed.). New York: Bloomsbury Press. 